\title{
Pharmacokinetics of morphine infusion in
}

\section{premature neonates}

\author{
R Hartley, M Green, M Quinn, M I Levene
}

\begin{abstract}
Morphine pharmacokinetics were studied in 17 premature neonates (26-34 weeks' gestation) after intravenous infusion during the first 24 hours of life. Infants received either standard dose morphine that comprised of a $100 \mu \mathrm{g} / \mathrm{kg} / \mathrm{hour}$ loading infusion for 2 hours followed by a maintenance infusion of $12.5 \mu \mathrm{g} / \mathrm{kg} / \mathrm{hour}$, or a high dose of $200 \mu \mathrm{g} / \mathrm{kg} / \mathrm{hour}$ for 2 hours followed by $50 \mu \mathrm{g} / \mathrm{kg} / \mathrm{hour}$. Mean plasma concentrations of morphine (SD) after 2 and 24 hours were $99(12.9)$ and 96.4 $(3 \cdot 2) \mathrm{ng} / \mathrm{ml}$, and $184 \cdot 2(37 \cdot 7)$ and 319 $(71 \cdot 2) \mathrm{ng} / \mathrm{ml}$ for the standard and high dose regimens, respectively. Morphine3-glucuronide plasma concentrations achieved about $20 \%$ and $80 \%$ of morphine values at 2 and 24 hours respectively. Morphine-6-glucuronide could not be detected at 2 hours, but attained $20-25 \%$ of morphine plasma concentrations by 24 hours. The population mean morphine clearance was $2.4 \mathrm{ml} / \mathrm{min} / \mathrm{kg}$, the elimination half life was 8.75 hours and the volume of distribution was $1.82 / \mathrm{kg}$. High plasma concentrations of morphine appeared to be well tolerated. Although mean arterial blood pressure decreased during the first six hours of treatment, this was not statistically significant; two infants experienced transient muscle rigidity, but no evidence of seizures was noted. There appears to be no clinical advantage in using the high dose regimen. (Arch Dis Child 1993; 69: 55-58)
\end{abstract}

Morphine is increasingly used as a sedative and analgesic in neonatal intensive care, particularly for the management of infants requiring mechanical ventilation during treatment of respiratory distress syndrome. ${ }^{1}$ Unfortunately, $25 \%$ of premature neonates continue to 'fight' the ventilator, despite relatively high doses of morphine ${ }^{2}$ and may require pancuronium to inhibit these spontaneous respirations. ${ }^{3}$ However, treatment with morphine may be preferential to pancuronium in reducing the stress of intensive care in preterm infants. ${ }^{2}$

The safe and effective use of morphine in premature neonates is complicated by the presence of active metabolites. Morphine-6glucuronide $(\mathrm{M} 6 \mathrm{G})$ is a potent analgesic ${ }^{4}$ and respiratory depressant, ${ }^{5}$ while morphine-3glucuronide (M3G) antagonises the analgesic effects of both morphine and $M 6 G,{ }^{67}$ and stimulates respiratory activity. ${ }^{8}$ Preterm infants can metabolise morphine by glucuronidation, but M3G:morphine plasma concentration ratios suggest that their metabolic capacity is reduced in comparison with children aged 1-16 years. ${ }^{9}$ Recent studies in premature neonates have also indicated developmental changes in the half life $\left(t^{1} / 2\right)^{10-12}$ and plasma clearance of morphine. ${ }^{1112}$ The reduced capacity for conversion of morphine to $\mathrm{M} 6 \mathrm{G}$ in premature neonates may compromise the efficacy of the drug within this patient group. Alternatively, the delay in clinical response may be due to inadequate plasma concentrations of morphine during the first $2-4$ hours of treatment. The increased risk of serious lung and brain complications in premature infants who actively expire against positive pressure inflation ${ }^{3}{ }^{13}$ prompted us to administer a loading dose of morphine as an intravenous infusion, followed by a constant rate infusion to provide effective plasma concentrations more rapidly, and to evaluate increases in dose rate. This study investigates the pharmacokinetics of the drug and disposition of its glucuronide metabolites in premature neonates (gestational age 26-34 weeks), who had received the standard or high dose regimen during the first 24 hours of life (postnatal age $<24$ hours at initiation of treatment).

\section{Patients and methods}

PATIENTS

Plasma concentrations of morphine were investigated in 17 premature neonates (nine boys) during the first 24 hours of treatment in order to provide population estimates of plasma clearance, $t^{1} / 2$, and volume of distribution. Infants' gestational age ranged from 26-34 weeks (mean (SD) 29.6 (2.03) weeks) postnatal age (on entry into the study) was $<1$ day in all cases, and birth weight ranged from 900 to $2260 \mathrm{~g}$ (mean (SD) 1330 (380) g). Details of individual patients are shown in table 1. All infants had respiratory distress syndrome and were receiving morphine intravenously to encourage synchronisation of their respiratory effort with the ventilator, as well as for analgesia.

\section{DOSAGE REGIMENS}

Two dosage regimens were used: standard dose morphine that comprised a $100 \mu \mathrm{g} / \mathrm{kg} /$ hour loading infusion for 2 hours, followed by a maintenance infusion of $12.5 \mu \mathrm{g} / \mathrm{kg} /$ hour and high dose that consisted of a $200 \mu \mathrm{g} / \mathrm{kg} / \mathrm{hour}$ loading infusion for 2 hours, followed by a constant rate infusion of $50 \mu \mathrm{g} / \mathrm{kg} /$ hour. The study was approved by the Leeds West Hospital ethics committee and informed parental consent was obtained before starting the infusion. Blood was obtained via an umbilical arterial catheter after $0,2,4,6,12$, and 24 hours of morphine treatment; however, only four 
Table 1 Clinical details, plasma concentrations of morphine and plasma clearance

\begin{tabular}{|c|c|c|c|c|c|c|c|}
\hline \multirow{2}{*}{$\begin{array}{l}\text { Patient } \\
\text { No }\end{array}$} & \multirow[b]{2}{*}{ Sex } & \multirow{2}{*}{$\begin{array}{l}\text { Birth } \\
\text { weight } \\
\text { (g) }\end{array}$} & \multirow{2}{*}{$\begin{array}{l}\text { Gestation } \\
\text { (weeks) }\end{array}$} & \multirow{2}{*}{$\begin{array}{l}\text { Dose } \\
\text { regimen } \\
\text { ( } \mu \text { g/kg/hour) }\end{array}$} & \multicolumn{2}{|c|}{ Plasma concentration $(\mathrm{ng} / \mathrm{ml})$} & \multirow{2}{*}{$\begin{array}{l}\text { Clearance } \\
(\mathrm{mL} / \mathrm{min} / \mathrm{kg})\end{array}$} \\
\hline & & & & & 2 hours & 24 hours & \\
\hline $\begin{array}{l}1 \\
2 \\
3 \\
4 \\
5 \\
6 \\
7 \\
8 \\
9\end{array}$ & $\begin{array}{l}F \\
F \\
F \\
M \\
M \\
M \\
F \\
F \\
M\end{array}$ & $\begin{array}{r}1000 \\
1010 \\
2260 \\
1320 \\
1080 \\
910 \\
1260 \\
1340 \\
1240\end{array}$ & $\begin{array}{l}28 \\
29 \\
34 \\
29 \\
26 \\
31 \\
28 \\
31 \\
28\end{array}$ & $\begin{array}{l}\text { lard dose } \\
100 \star / 12 \cdot 5 \dagger \\
100 / 12 \cdot 5 \\
100 / 12 \cdot 5 \\
100 / 12 \cdot 5 \\
100 / 12 \cdot 5 \\
100 / 12 \cdot 5 \\
100 / 12 \cdot 5 \\
100 / 12 \cdot 5 \\
100 / 12 \cdot 5\end{array}$ & $\begin{array}{r}106 \\
103 \\
99 \\
110 \\
77 \\
- \\
- \\
- \\
-\end{array}$ & $\begin{array}{l}- \\
96 \\
- \\
- \\
- \\
93 \\
94 \\
98 \\
101\end{array}$ & $\begin{array}{c}- \\
2 \cdot 17 \\
- \\
- \\
- \\
2 \cdot 24 \\
2 \cdot 22 \\
2 \cdot 13 \\
2 \cdot 06\end{array}$ \\
\hline Mean & & $1270(400)$ & $29 \cdot 3(2 \cdot 3)$ & & $99 \cdot 0(12 \cdot 9)$ & $96 \cdot 4(3 \cdot 2)$ & $2 \cdot 16(0 \cdot 1)$ \\
\hline $\begin{array}{l}10 \\
11 \\
12 \\
13 \\
14 \\
15 \\
16 \\
17\end{array}$ & $\begin{array}{l}F \\
F \\
M \\
M \\
F \\
M \\
M \\
M\end{array}$ & $\begin{array}{r}960 \\
900 \\
1700 \\
1720 \\
1350 \\
1680 \\
1800 \\
1460\end{array}$ & $\begin{array}{l}27 \\
27 \\
31 \\
31 \\
31 \\
31 \\
31 \\
29\end{array}$ & $\begin{array}{l}h \text { dose } \\
200 / 50 \\
200 / 50 \\
200 / 50 \\
200 / 50 \\
200 / 50 \\
200 / 50 \\
200 / 50 \\
200 / 50\end{array}$ & $\begin{array}{l}128 \\
194 \\
161 \\
200 \\
141 \\
203 \\
206 \\
241\end{array}$ & $\begin{array}{c}- \\
- \\
298 \\
298 \\
258 \\
- \\
\overline{422}\end{array}$ & $\begin{array}{c}- \\
- \\
2 \cdot 80 \\
2 \cdot 80 \\
3 \cdot 23 \\
- \\
- \\
1 \cdot 97\end{array}$ \\
\hline Mean & & $1450(400)$ & $29 \cdot 8(1 \cdot 8)$ & & $184 \cdot 2(37 \cdot 7)$ & $319(71 \cdot 2)$ & $2.70(0.5)$ \\
\hline
\end{tabular}

*2 hour loading infusion; fconstant rate infusion.

samples were taken from any one baby (approximately $0.6 \mathrm{ml}$ per sample) to minimise the blood volume requirement per patient. Plasma was separated and stored at $-70^{\circ} \mathrm{C}$ before analysis.

\section{CLINICAL OBSERVATIONS}

All infants received regular monitoring of blood pressure, heart rate, respiratory rate, blood gases, ventilator rate, and blood glucose. Infants receiving the high dose regimen, however, had their blood pressure continuously monitored via an umbilical arterial catheter, for at least six hours after commencement of morphine infusion, and these babies were closely observed for evidence of seizures during the first 24 hours.

\section{ANALYTICAL METHODS}

Morphine, M3G, and M6G were measured in plasma using a reversed phase ion pair high performance liquid chromatographic method specifically developed for this study. ${ }^{14}$

\section{PHARMACOKINETIC CALCULATIONS}

An estimate of the population mean plasma clearance was obtained by dividing the morphine infusion rate by the apparent steady state plasma concentration of morphine after 24 hours of treatment. This population mean plasma clearance $(\mathrm{Clp})$ value was used to simulate plasma concentration-time profiles for a range of $t^{1} / 2$ values ( $8-9$ hours), using standard pharmacokinetic calculations, ${ }^{15}$ equations (1) and (2), for determining the plasma concentration at steady state (Css) and the plasma concentration at time $t(C)$, after a constant rate infusion

$$
\begin{aligned}
\text { Css } & =\text { infusion } \mathrm{rate} / \mathrm{Clp} \\
\mathrm{C} & =\operatorname{Css}\left[1-(1 / 2)^{\mathrm{n}}\right]
\end{aligned}
$$

where $n$ is expressed in multiples of the $t^{1} / 2$ of the drug (that is $n$ is the time $t$ divided by $t^{1 / 2}$ ). An estimate of the population mean $t^{1 / 2}$ was subsequently obtained by superimposing mean (SE) measured plasma concentrations of morphine in samples from premature neonates (at 2, 4, 6, 12, and 24 hours for the standard dose, and 2 and 24 hours for the high dose regimens, respectively) onto these simulated plasma concentration-time curves, and examining for 'best fit'. The population mean volume of distribution (Vd) was calculated from estimates of plasma clearance and $t^{1 / 2}$ thus obtained, using equation (3)

$$
\mathrm{Vd}=\mathrm{Clp} \times \mathrm{t}^{1 / 2} / 0 \cdot 693
$$

\section{STATISTICAL ANALYSIS}

Results are given as mean (SD). The difference between mean plasma clearance values for the standard and high dose regimens, and changes in mean arterial blood pressure, were assessed by the Mann-Whitney $U$ test. Relationships between birth weight or gestational age and plasma clearance were investigated using Spearman's rank correlation analysis. A $\mathrm{p}$ value of $<0.05$ was considered to be statistically significant.

\section{Results}

PLASMA CONCENTRATIONS

Morphine was detected in all plasma samples obtained from 2 hours through to 24 hours, irrespective of dosage regimen (figure). Mean (SD) plasma concentrations were 99 (12.9), $110(39 \cdot 6), 104(32 \cdot 6), 108(35 \cdot 4)$, and $96 \cdot 4$ $(3.2) \mathrm{ng} / \mathrm{ml}$ for the standard dose regimen at 2 , $4,6,12$, and 24 hours, respectively; mean (SD) values for the high dose regimen were $184 \cdot 2(37 \cdot 7)$ and $319(71 \cdot 2) \mathrm{ng} / \mathrm{ml}$ at 2 and 24 hours, respectively. M3G could be measured in all samples obtained at 2 hours and 24 hours, mean (SD) plasma concentrations were $20.7(7.6)$ and $33.3(14.3) \mathrm{ng} / \mathrm{ml}$ at 2 hours, and $61.8(33.7)$ and $273.5(71.4) \mathrm{ng} / \mathrm{ml}$ at 24 hours, for the standard and high dose regimens, respectively. In contrast, plasma concentrations of M6G could not be detected in samples obtained at 2 hours, irrespective of dose, but were measured in 24 hour samples (mean (SD) $19.2(6.7)$ and $78(23.8) \mathrm{ng} / \mathrm{ml}$ for the standard and high dose regimens, respectively). 


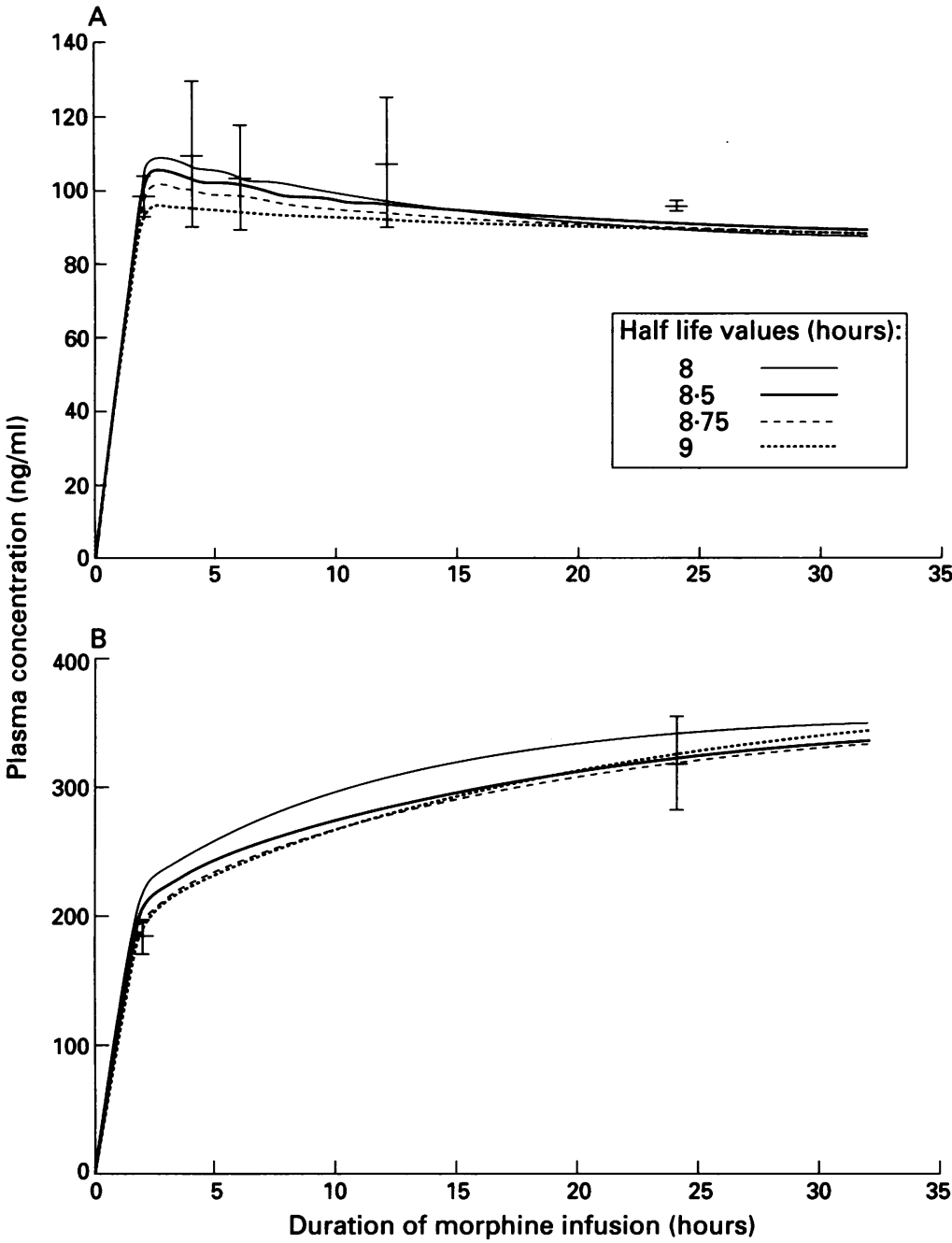

Mean (SE) plasma concentrations of morphine measured in samples obtained from premature neonates (at 2, 4, 6, 12 and 24 hours, and 2 and 24 hours for the standard and high dose regimens, respectively) superimposed on simulated plasma concentration-time profiles, based on the population mean plasma clearance $(2.4 \mathrm{ml} / \mathrm{min} / \mathrm{kg})$ and half life $\left(t^{1} / 2\right)$ values of $8,8 \cdot 5,8 \cdot 75$, and 9 hours for the two dose regimens. Visual examination for 'best fit' between mean measured values and simulated data for the standard dose $(A)$ and high dose (B) regimens, indicates a population mean $t^{1 / 2}$ close to 8.75 hours.

\section{PHARMACOKINETICS}

Plasma clearance values for individual patients, derived from 24 hour morphine plasma concentrations, are shown in table 1 . The difference between mean plasma clearance values for the standard and high dose regimens was not statistically significant. Trends suggesting an increase in the clearance of morphine with increasing birth weight and gestational age were observed, but these did not achieve significance $(r=0.310$ and 0.630 , respectively; nine data pairs, $p>0.05$ ). The population mean clearance of morphine was $2.4 \mathrm{ml} / \mathrm{min} / \mathrm{kg}(\mathrm{n}=9)$. The population mean

Table 2 Mean arterial blood pressure $(\mathrm{mm} \mathrm{Hg})$ in infants receiving the high dose regimen

\begin{tabular}{llllllll}
\hline \multicolumn{7}{l}{ Duration of morphine infusion (hours) } \\
\cline { 2 - 9 } Patient No & 0 & 1 & 2 & 3 & 4 & 5 & 6 \\
\hline 1 & 32 & 28 & 30 & 36 & 33 & 35 & 35 \\
2 & 52 & 50 & 47 & 47 & 47 & 43 & 45 \\
3 & 51 & 40 & 38 & 40 & 41 & 36 & 39 \\
4 & 39 & 35 & 30 & 30 & 30 & 30 & 31 \\
5 & 36 & 32 & 34 & 38 & 38 & 39 & 39 \\
6 & 43 & 45 & 42 & 43 & 43 & 42 & 39 \\
7 & 42 & 43 & 42 & 42 & 41 & 40 & 40 \\
Mean (SD) & $42 \cdot 1(7 \cdot 4)$ & $39 \cdot 0(7 \cdot 8)$ & $37 \cdot 6(6 \cdot 5)$ & $39 \cdot 4(5 \cdot 5)$ & $39 \cdot 0(5 \cdot 9)$ & $37 \cdot 9(4 \cdot 5)$ & $38 \cdot 3(4 \cdot 4)$ \\
$\%$ Decrease & - & $7 \cdot 4$ & $10 \cdot 7$ & $6 \cdot 4$ & $7 \cdot 4$ & $10 \cdot 0$ & $9 \cdot 0$ \\
\hline
\end{tabular}

$\mathrm{t}^{1} / 2$ for morphine was found to be 8.75 hours. This value provided the 'best fit' when mean (SE) measured plasma concentrations of morphine were superimposed on simulated plasma concentration-time profiles (using $\mathrm{t}^{1 / 2} / 2$ values from 8-9 hours) for the standard and high dose regimens (figure). The population mean volume of distribution derived from these two pharmacokinetic parameters was $1.82 \mathrm{l} / \mathrm{kg}$.

\section{CLINICAL OBSERVATIONS}

Mean arterial blood pressure data from seven infants receiving the high dose regimen are presented in table 2. Although mean blood pressure decreased between $6 \cdot 4-10 \cdot 7 \%$ during the first 6 hours of morphine infusion, these changes were not statistically significant $(p>0.05)$; the largest decrease noted after 2 hours coincided with the completion of the loading infusion. Despite careful observation, there was no indication of seizures during the first 24 hours, but we did note transient hypertonia in two infants.

\section{Discussion}

The need for multiple samples in pharmacokinetic studies involving premature neonates can present a problem. Clearly, the volume of blood that can justifiably be obtained from acutely ill preterm infants is limited, particularly in the first 24 hours of treatment. The approach outlined in this study, using simulation techniques, provides a way of obtaining population estimates of pharmacokinetic parameters and minimises the sample requirement to only four samples per infant. The population mean morphine plasma clearance of $\mathbf{2 \cdot 4}$ $\mathrm{ml} / \mathrm{min} / \mathrm{kg}$ is slightly lower than previously published values of $4.7,3.39$, and 3.6 $\mathrm{ml} / \mathrm{min} / \mathrm{kg}$ in preterm infants, ${ }^{911} 12$ but this may be due to differences in postnatal age between the present ( $<1$ day) and earlier study populations ( $>2$ days). Morphine plasma clearance showed a tendency to increase with birth weight and gestational age; though not statistically significant, these trends reflect the developmental changes in morphine clearance reported by Bhat et al ${ }^{11}$ and Barrett et al. ${ }^{12}$ Mean plasma clearance values for the standard and high dose regimens were not significantly different, supporting the view that the metabolism of morphine is not dose dependent. ${ }^{16}$ The population mean $t^{1} / 2$ for morphine of 8.75 hours is in good agreement with values of 10.3 , 10 , and 8.9 hours reported for premature neonates. ${ }^{10-12}$ All of these earlier studies noted a decrease in morphine half life with increasing postconceptional or gestational age. The population mean volume of distribution of $1.821 / \mathrm{kg}$ concurs with published values of 1.84 and 2.7 $1 / \mathrm{kg}^{1112}$; this range of values may also reflect differences in postnatal age between study populations.

Mean morphine plasma concentrations measured in samples obtained at 2 and 24 hours (99.0 and $96.4 \mathrm{ng} / \mathrm{ml}$, respectively), from infants receiving the standard dose regimen, are in good agreement with the predicted steady state concentration $(86.8 \mathrm{ng} / \mathrm{ml})$ derived from the population mean plasma 
clearance $(2.4 \mathrm{ml} / \mathrm{min} / \mathrm{kg})$; this suggests that steady state plasma concentrations are achieved rapidly and within 2 hours. For the high dose regimen, the mean measured morphine plasma concentration at 24 hours (319 $\mathrm{ng} / \mathrm{ml}$ ) indicates that this regimen achieves about $92 \%$ of the predicted steady state plasma concentration $(347 \cdot 2 \mathrm{ng} / \mathrm{ml})$ by this time.

The mean plasma morphine concentrations obtained after a 2 hour loading infusion (99.0 and $184.2 \mathrm{ng} / \mathrm{ml}$ for the standard and high dose regimens, respectively), exceed the reported minimum concentrations required for analgesia in children. ${ }^{17}$ On this basis, both dosage regimens appear to produce effective plasma concentrations of morphine within 2 hours. The plasma concentrations of morphine necessary to ensure adequate analgesia, and/or to suppress spontaneous respirations, in premature neonates remain unclear. Developmental changes in the pharmacokinetics of morphine ${ }^{10-12}$ imply that for a given dose, preterm infants will achieve a higher plasma concentration of morphine for a longer duration than full term neonates or older babies. It has been suggested that young infants are particularly sensitive to respiratory depression. ${ }^{18}$ Though an undesirable side effect in unventilated infants, respiratory depression is potentially beneficial in preventing the baby breathing out of synchrony with the ventilator in infants with respiratory distress syndrome. Despite efforts to optimise morphine dosage regimens by ensuring adequate plasma concentrations of morphine within 2 hours, $25 \%$ of premature neonates continue to fight the ventilator. As the glucuronides have been shown to have opposing effects on respiratory effort (M6G is a respiratory depressant ${ }^{5}$ while M3G has been shown to be a respiratory stimulant ${ }^{8}$ ), the relative plasma concentrations of $\mathrm{M} 3 \mathrm{G}$ and $\mathrm{M} 6 \mathrm{G}$ may be important. It is of interest that at the time pancuronium is added to inhibit spontaneous respirations (usually within 2-4 hours), plasma concentrations of M6G after morphine infusion are virtually undetectable in premature neonates, irrespective of dose, whereas M3G plasma concentrations achieve about $20-30 \%$ of morphine plasma concentrations. This imbalance in plasma concentrations of the active metabolites may be the reason that some preterm infants continue to struggle against the ventilator. Alternatively, the variability in clinical response could be due to differences in the development of opiate receptors or the permeability of the bloodbrain barrier.

The relatively high morphine plasma concentrations resulting from the high dose regimen $(182.4$ and $319 \mathrm{ng} / \mathrm{ml}$ at 2 and 24 hours, respectively) were well tolerated. Mean blood pressure decreased during the first six hours, the maximum change $(10 \cdot 7 \%)$ was noted at 2 hours corresponding with completion of the loading infusion. However, the changes in mean blood pressure were not statistically significant and were not associated with clinical deterioration. Indeed, although we have data from only seven infants, these changes may reflect a transition from higher blood pressure values in stressed babies to more normal values as the sedative and analgesic effects of morphine settle the infants. Giving the loading dose over 2 hours appears to alleviate concern regarding reductions in blood pressure when opioid drugs are given as an intravenous bolus. ${ }^{19}$ Despite careful clinical observation, we found no evidence to support the view that high plasma morphine concentrations are associated with seizures. ${ }^{20} \mathrm{We}$ did note transient hypertonia in two infants but this did not necessitate termination of the morphine infusion. As clinical effect seems to be unaffected by dosage increment, there appears to be no advantage in using the high dose regimen.

1 Elias-Jones AC, Barrett DA, Rutter N, Shaw PN, Davis SS. Diamorphine infusion in the preterm infant. Arch Dis Child 1991; 66: 1155-7

2 Quinn MW, Otoo F, Rushforth JA, et al. Effect of morphine and pancuronium on the stress response in ventilated preterm infants. Early Hum Dev 1992; 30: 241-8.

3 Greenough A, Morley CJ, Wood S, Davis JA. Pancuronium prevents pneumothoraces in ventilated premature babies who actively expire against positive pressure inflation. Lancet 1984; i: $1-3$.

4 Osborne R, Joel S, Trew D, Slevin M. Morphine and metabolite behaviour after different routes of morphine administration: demonstration of the importance of the active metabolite morphine-6-glucuronide. Clin Pharmacol Ther 1990; 47: 12-9.

5 Hasselstrom J, Berg U, Lofgren A, Sawe J. Long lasting respiratory depression induced by morphine-6-glucuronide? Br 7 Clin Pharmacol 1989; 27: 515-8.

6 Smith MT, Watt JA, Cramond T. Morphine-3-glucuronide - a potent antagonist of morphine analgesia. Life Sci 1990; 47: 579-85.

7 Watt JA, Cramond T, Smith MT. Morphine-6glucuronide: analgesic effects antagonized by morphine3-glucuronide. Clin Exp Pharmacol Physiol 1990; 17 suppl: 83.

8 Gong Q-L, Hedner T, Hedner J, Bjorkman R, Nordberg G. Antinociceptive and ventilatory effects of the morphine metabolites: morphine-6-glucuronide and morphine-3glucuronide. Eur $\mathcal{f}$ Pharmacol 1991; 193: 47-56.

9 Choonara IA, McKay P, Hain R, Rane A. Morphine metabolism in children. Br f Clin Pharmacol 1989; 28: 599-604

10 Mercurio M, Nelli C, Gettner P, Sherwonit E, Williams J, Ehrenkranz R. Morphine pharmacokinetics in premature newborns. Pediatr Res 1989; 25 (71A): A408.

11 Bhat R, Chari G, Gulati A, Aldana O, Velamati R, Bhargava H. Pharmacokinetics of a single dose of morphine in preterm infants during the first week of life. $\mathscr{f}$ Pediatr preterm infants du

12 Barrett DA, Elias-Jones AC, Rutter N, Shaw PN, Davis SS. Morphine kinetics after diamorphine infusion in premature neonates. Br f Clin Pharmacol 1991; 32: 31-7.

13 Perlman JM, Goodman S, Kreusser KL, Volpe JJ. Reduction in intraventricular hemorrhage by elimination of fluctuating cerebral blood-flow velocity in preterm infants with respiratory distress syndrome. $N$ Engl $\mathcal{F} M e d$ 1985; 312: 1353-7.

14 Hartley $R$, Green $M$, Quinn $M$, Levene MI. Analysis of morphine and its 3- and 6-glucuronides by high performance liquid chromatography with fluorometric detection ance liquid chromatography with fluorometric detection
following solid phase extraction from neonatal plasma.

15 Rowland M, Tozer TN. Clinical pharmacokinetics: concepts and applications. 2nd Ed. Philadelphia: Lea and Febiger, 1989.

16 Sawe J, Svensson JO, Rane A. Morphine metabolism in cancer patients on increasing oral doses - no evidence for autoinduction or dose-dependence. Br f Clin Pharmacol 1983; 16: 85-93.

17 Dahlstrom B, Boline P, Feychting H, Noack G, Paalzour L. Morphine kinetics in children. Clin Pharmacol Ther 1979; 26: 354-65.

18 Lynn AM, Slattery JT. Morphine pharmacokinetics in early infancy. Anesthesiology 1987; 66: 136-9.

19 Marlow N, Weindling AM, Cooke RWI. Hazards of analgesia for newborn infants. Arch Dis Child 1988; 63: 1293.

20 Koren G, Butt W, Chinyanga H, Soldin S, Tan YK, Pape $K$. Postoperative morphine infusion in newborn infants: assessment of disposition characteristics and safety. $\mathcal{J}$ Pediatr 1985; 107: 963-7. 